\title{
Effects of unpredictability versus loss of predictability of shock on gastric lesions in rats
}

\author{
AKIRA TSUDA, MASATOSHI TANAKA, and TADASHI NISHIKAWA \\ Kurume University School of Medicine, Kurume, Japan \\ HISASHI HIRAI \\ Sophia University, Tokyo, Japan \\ and \\ WILLIAM P. PARÉ \\ Veterans Administration Medical Center, Perry Point, Maryland
}

\begin{abstract}
The relative importance of unpredictability versus loss of predictability of electric tailshock affecting stress pathology was assessed by using an index of the severity of gastric lesions in male Sprague-Dawley rats. Although repeated sessions of unpredictable shock produced more severe gastric lesions in a greater percentage of rats than did repeated sessions of either predictable or no shock, there was no significant difference, in terms of both incidence and severity of lesions, between lack of predictability and loss of predictability. However, rats exposed first to unpredictable shock and subsequently to predictable shock had significantly fewer lesions than rats exposed continuously to unpredictable shock. The results emphasize only the deleterious effects of shock unpredictability. The effects of changes in predictability of shock on gastric erosions are not clearly supported by the results.
\end{abstract}

Recent studies with animals have emphasized the importance of psychological variables such as unpredictability of shock in the regulation of internal reactions to stress, particularly in the formation of gastric lesions (Seligman \& Binik, 1977; Weiss, 1977). Weiss (1970) demonstrated that rats that received a warning signal prior to electric shock developed less extensive gastric erosions than did their partners, which received exactly the same number and intensity of shocks but were not presented with the warning stimulus.

In a comprehensive review of the literature on experimental neurosis, Mineka and Kihlstrom (1978) noted the importance of the lack of predictability versus the loss of predictability of shock. Most investigations have emphasized only the importance of lack of predictability of shock (i.e., unpredictability) (Fanselow, 1980; Paré \& Livingston, 1975; Seligman, 1968; Quirce, Odio, \& Solano, 1981). With regard to the effects of

This work was supported by a postgraduate scholarship awarded by the Association for the Advancement of Sciences of Japan to the first author. Request for reprints should be directed to Akira Tsuda, Department of Pharmacology, Kurume University School of Medicine, Kurume 830, Japan. (M. Tanaka and T. Nishikawa are associated with the Department of Pharmacology, H. Hirai with the Department of Psychology, and W. P. Pare with the Pavlovian Research Laboratory of their respective institutions.) loss of controllability, some experiments have revealed that loss of controllability over an aversive outcome, given prior history of control, appeared to be more stressful than never having had control over the aversive event (Hanson, Larson, \& Snowdon, 1976; Seligman, 1975; Tsuda, Tanaka, Nishikawa, \& Hirai, 1983; Weiss, 1971). On the other hand, as pointed out by Mineka and Kihlstrom (1978), there seems to be a complete lack of research on the loss of shock predictability. When we consider the detrimental effects of loss of controllability over an aversive event on somatic disturbance to animals, we might expect that loss of predictability of shock would produce more profound disturbance in animals with prior predictability experience than it would in animals without it.

The present study was an initial attempt to determine whether change in the predictability of shock (i.e., exposure first to a predictable shock condition and then to an unpredictable shock condition) would result in more severe gastrointestinal disease than would treatment conditions wherein either predictable shock or unpredictable shock situations remained the same and were not switched during the experimental period. The effects of these treatment conditions were evaluated by comparing the development of gastric erosions in all treatments. 


\section{METHOD}

\section{Subjects and Apparatus}

The subjects, which consisted of 64 male Sprague-Dawley rats weighing approximately $170 \mathrm{~g}$, were housed in single cages and maintained ad lib on water and food.

The apparatus consisted of eight Plexiglas chambers $(9 \mathrm{~cm}$ wide, $19.5 \mathrm{~cm}$ long, and $15 \mathrm{~cm}$ high) placed in soundproof boxes. The end walls of each apparatus were at an angle, and the top fitted across the rat's back to prevent the rat from backing out during the session. The rat's tail extended through a hole in the rear of each chamber and was held in place by a small piece of tubing taped to the tail. Electric shock was produced by a Grason-Stadller shocker scrambler and applied through copper-clip electrodes attached to the tail. A 95-dB $(1250 \mathrm{~Hz})$ tone in conjunction with background white noise at $80 \mathrm{~dB}$ originated from an audio generator and was delivered through a speaker attached to the inside of each soundproof box. Presentation of stimulus events was controlled by electromechanical equipment.

\section{Procedure}

Eight rats, matched for body weight (within $10 \mathrm{~g}$ of each other), were used at one time. The animals were food-deprived $24 \mathrm{~h}$ prior to the initial stress session. On Day 1 , two subjects were selected randomly and assigned to one of the two nonshock control conditions. These rats never received shock but simply remained in their chambers. The other six subjects received shock $(1.5 \mathrm{~mA}, 1-\mathrm{sec}$ duration) on a variable-interval 1-min schedule over the 24 -h period. The tail electrodes for the animals were wired in series so that the shock received by these subjects was of exactly the same current intensity and duration. Three subjects, which were designated as the predictable shock group, received a 10 -sec tone signal that began $10 \mathrm{sec}$ before each shock. The three other shock subjects, designated as the unpredictable shock group, received the same signal, but it was programmed randomly so that it occurred with no temporal relationship to the shock.

On Day 2, after the initial stress session, one rat from each experimental group-nonshock, predictable shock, and unpredictable shock-was sacrificed and its stomach removed for inspection. The five remaining rats (i.e., one from the nonshock, two from the predictable shock, and two from the unpredictable shock groups) were returned to their individual home cages, where food was provided ad lib. On Day 3, after 24-h feeding, food was removed from all cages.

Twenty-four hours later, on Day 4, five rats were again placed in their respective experimental chambers. The one rat from the nonshock group received the same nonshock treatment it had received on Day 1 (i.e., a non-nonshock condition). One of the rats from the predictable shock group again received the predictable shock, which was the same as in the initial stress session on Day 1 (i.e., predictable-predictable shocks). The other rat from the predictable shock group, however, was now exposed to the unpredictable shock treatment as described above (i.e., predictable- unpredictable shocks). One rat from the unpredictable shock group was again exposed to unpredictable shock (i.e., unpredictable-unpredictable shocks), while the other rat from the unpredictable shock group was given another exposure of predictable shock (i.e., unpredictable-predictable shocks).

On Day 5, $24 \mathrm{~h}$ after the second stress session, the animals were removed from the chambers and immediately sacrificed by ether. The stomachs were opened, and lesions were scored by an observer who was blind to the treatment conditions and who used the method of Fujiwara and Mori (1970) to record the severity of erosion. Briefly, a score of 0 was given to no change, 1 to small hemorrhagic points and edemas, 2 to one or two small (smaller than $2 \mathrm{~mm}$ in diameter) mucosal defects, and 3 to many small mucosal defects. The procedure was conducted eight times, thereby yielding eight subjects for each of the eight treatment conditions.

Statistical comparisons were made by Kruskal-Wallis test on gastric lesion data. Comparisons between individual groups were then carried out using Mann-Whitney's $U$ test ( $p<.05$ or less). Also, comparisons of the incidence of gastric lesions among groups were performed using the Fisher exact probability test.

\section{RESULTS}

A nonparametric Kruskal-Wallis test revealed a significant group effect on gastric pathology $\left[\chi^{2}(7)\right.$ $=24.66, \mathrm{p}<.01]$, as shown in Table 1. Following the initial stress session, none of the rats in the nonshock group showed any lesions. The rats in the unpredictable shock group formed significantly more lesions than the nonshock group in terms of both incidence and severity of gastric lesions. The predictable shock group did not differ significantly from these two groups.

Following the second stress session, three of the shocked groups (not including the predictablepredictable shock group) developed significantly more gastric lesions than did the nonshock group. All rats in the unpredictable-unpredictable shock group exhibited glandular lesions, while half of the rats in the predictable-predictable shock group exhibited lesions. The median ulcer index was significantly higher for the unpredictable-unpredictable shock group than for each of the predictable-predictable shock, unpredictable-predictable shock, non-nonshock, and predictable shock groups. The predictable-unpredictable shock group exhibited significantly more lesions than did the non-nonshock and predictable-shock groups.

Table 1

Summary of Stomach Condition for the Eight Treatments

\begin{tabular}{lccc}
\hline \multicolumn{1}{c}{ Treatment } & Number of Subjects & Rats with Ulcers & Median Ulcer Index Per Rat \\
\hline Nonshock & 8 & 0 & 0.0 \\
Predictable Shock & 8 & 2 & 0.0 \\
Unpredictable Shock & 8 & $5^{*}$ & $1.0^{*}$ \\
Non-Nonshock & 8 & 1 & 0.0 \\
Predictable-Predictable Shock & 8 & $4 *$ & 0.5 \\
Predictable-Unpredictable Shock & 8 & $7^{*}, * *, \dagger$ & $1.5 *, * *, \dagger$ \\
Unpredictable-Unpredictable Shock & 8 & $8^{*}, * *, \dagger, \dagger \dagger$ & $3.0^{*}, * *, \dagger, \dagger \dagger$ \\
Unpredictable-Predictable Shock & 8 & $5^{*}$ & $1.0^{*}, \dagger \dagger \dagger$ \\
\hline
\end{tabular}

Note $p<.05$ or less. $\quad$ *Significantly different from the nonshock. **Significantly different from the non-nonshock. †Significantly different from the predictable shock. ItSignificantly different from the predictable-predictable shock. ††+Significantly different from the unpredictable-unpredictable shock. 


\section{DISCUSSION}

The present study was performed to explore the effects of unpredictability of shock versus loss of predictability of shock on gastric pathology in rats. The data herein do not support our presumption that loss of predictability of shock may have more deleterious consequences than mere lack of predictability. Thus, our hypothesis about the effects of changes in predictability of shock on gastric erosions are not clearly supported by the results.

The gastric pathology of rats given predictable shock followed by unpredictable shock did not differ significantly from that of rats given repetitive sessions of either unpredictable or predictable shock. Unpredictable shock following predictable shock did not add more to the ulcerogenic effects than did unpredictable shock following unpredictable shock. Apparently, loss of predictability of shock does not contribute anything to gastric damage beyond that produced by last exposure to the unpredictable shock condition. In this sense, a prior experience with predictable shock provides no immunization effects which would attenuate the impact of unpredictable shock in a later stress session.

This experiment suggests that the influence on gastric pathogenesis of a psychological variable such as loss of controllability is greater than the loss of shock predictability. Although the present experiment provides no support for the idea that the loss of predictability might produce more profound disturbances than might lack of predictability (Mineka \& Kihlstrom, 1978), some experiments reveal that loss of controllability over shocks, given prior experience of control, is more stressful than never having had control over them (Seligman, 1975; Weiss, 1971).

Repetitive sessions induced more gastric damage than did a single session, regardless of whether shock was predictable or unpredictable. There were, however, no significant differences in the total gastric lesions for these groups. Rats given unpredictable shock followed by predictable shock had a significantly lower gastric erosion index than did the rats given two sessions of unpredictable shock, even though the first exposure of unpredictable shock might have retarded the acquisition of the tone-shock relationship at a later session, as claimed by Mackintosh (1973), as "learned irrelevance." These results are interpreted to mean that unpredictable shock in first exposure induces substantial changes in gastric mucosa, which persist for less than $72 \mathrm{~h}$. Predictable shock given in the second session did not virtually produce the lesions. It is unlikely that the switch from the toneshock noncontingency condition to the tone-shock contingency (i.e., gain of predictability of shock) is the process that was responsible for the ameliorated effects observed.
Rats that received repetitive sessions of predictable shock developed fewer gastric lesions than did rats exposed to repetitive sessions of unpredictable shock. This finding is in agreement with previous reports that stated that unsignaled aversive events appeared to be more stressful than signaled ones (Seligman, 1968; Weiss, 1970). Predictability of shock in itself appears to be a factor that can ameliorate an organism's physiological reaction to shock.

Despite the difficulty in making clear-cut interpretations regarding the etiological mechanisms (Badia, Harsh, \& Abbot, 1979; Davis \& Levine, 1982; Imada \& Nageishi, 1982; Scheuer \& Greenberg, 1982; Tsuda, Tanaka, Hirai, \& Paré, 1983), it is reasonable to suggest, on the basis of the safety-signal hypothesis (Seligman \& Binik, 1977), that both unpredictability and loss of predictability of shock have many deleterious consequences on the ulcerogenesis process because animals that have no safety signal (i.e., no tone that indicates time out from shock) are the most stressed and consequently will continue to be subjected chronically to fear.

\section{REFERENCES}

Badia, P., Harsh, J., \& Аввот, B. Choosing between predictable and unpredictable shock conditions: Data and theory. Psychological Bulletin, 1979, 86, 1107-1131.

Davis, H., \& Levine, S. Predictability, control, and the pituitaryadrenal response in rats. Journal of Comparative and Physiological Psychology, 1982, 96, 393-404.

FANSELOW, M. S. Signaled shock-free periods and preference for signaled shock. Journal of Experimental Psychology: Animal Behavioral Processes, 1980, 6, 65-80.

Fujiwara, M., \& Mori, J. Experimental stress ulcer and biogenic amines. Saishin Igaku, 1970, 25, 2058-2067.

Hanson, J. D., Larson, M. E., \& Snowdon, C. T. The effects of control over high intensity noise on plasma cortisol levels in rhesus monkeys. Behavioral Biology, 1976, 16, 333-340.

IMADA, H., \& NAGEISHI, Y. The concept of uncertainty in animal experiments using aversive stimulation. Psychological Bulletin, 1982, 91, 573-588.

Mackintosh, N. J. Stimulus selection: Learning to ignore stimuli that predict no change in reinforcement. In R. A. Hinde \& $J$. Stevenson-Hinde (Eds.), Constraints on learning. New York: Academic Press, 1973.

Mine кA, S., \& Kinlstrom, J. F. Unpredictable and uncontrollable events: A new perspective on experimental neurosis. Journal of Abnormal Psychology, 1978, 87, 256-271.

Paré, W. P., \& Livingston, A., Jr. Shock predictability and plasma gastrin in the rat. Bulletin of the Psychonomic Society, 1975, 5, 289-291.

Quirce, C. M., Odio, M., \& Solano, J. M. The effects of predictable and unpredictable schedules of physical restraint upon rats. Life Sciences, 1981, 28, 1897-1902.

Scheuer, C., \& Greenberg, M. S. Preference for predictable vs. controllable shock. Bulletin of the Psychonomic Society, 1982, 19, 307-310.

Seligman, M. E. P. Chronic fear produced by unpredictable electric shock. Journal of Comparative and Physiological Psycho$\log y, 1968,66,402-411$.

Seligman, M. E. P. Helplessness: On depression, development and death. San Francisco: Freeman, 1975. 
Seligman, M. E. P., \& Binik, Y. M. The safety signal hypothesis. In H. Davis \& H. M. B. Hurwitz (Eds.), OperantPavlovian interactions. Hillsdale, N.J: Wiley, 1977.

Tsuda, A., Tanaka, M., Hirai, H., \& Paré, W. P. Effects of coping behavior on gastric lesions in rats as a function of predictability of shock. Japanese Psychological Research, 1983, 25, 9-15.

Tsuda, A., Tanaka, M., Nishikawa, T., \& Hirai, H. Effects of coping behavior on gastric lesions in rats as a function of the complexity of the coping task. Physiology \& Behavior, 1983, 30, 805-808.

WEISS, J. M. Somatic effects of predictable and unpredictable shock. Psychosomatic Medicine, 1970, 77, 14-21.
WEISS, J. M. Effects of punishing the coping response (conflict) on stress pathology in rats. Journal of Comparative and Physiological Psychology, 1971, 77, 14-21.

We iss, J. M. Psychological and behavioral influences on gastrointestinal lesions in animal models. In J. D. Maser \& M. E. P. Seligman (Eds.), Psychopathology: Experimental models. San Francisco: Freeman, 1977.

(Manuscript received June 20, 1983; revision accepted for publication October 11, 1983.) 